\title{
Influences of Silicon on Properties of Hard Drawn Aluminium Wire
}

\author{
XueXia XU ${ }^{1, a^{*}}$, YanTing FENG ${ }^{1, b}$, DongYu LIU ${ }^{2,3, \mathrm{c}}$, Yong $\mathrm{WANG}^{1, \mathrm{~d}}$, WenBin $\mathrm{LI}^{1, \mathrm{e}}$, \\ KangHua YAN ${ }^{2, \mathrm{f}}$ and BaoRang $\mathrm{LI}^{2,3, \mathrm{~g}}$ \\ ${ }^{1}$ State Grid Hebei Electric Power Research Institute, Shijiazhuang, 050021, China \\ ${ }^{2}$ School of Energy, Power and Mechanical Engineering, North China Electric Power University, \\ Beijing, 102206, China \\ ${ }^{3}$ National Thermal Power Engineering \& Technology Research Center, Beijing, 102206, China \\ axuxuexia2008@163.com, ${ }^{\mathrm{b}} 13503206410 @ 163 . c o m,{ }^{c}$ liudy@ncepu.edu.cn, ${ }^{\mathrm{d}} 15930172780 @ 163 . c o m$, \\ ewenbinli1975@126.com, ${ }^{\mathrm{f}} 252988432 @$ qq.com, ${ }^{\mathrm{g}}$ libr@ncepu.edu.cn
}

\begin{abstract}
Influences of $\mathrm{Si}$ content on the tensile strength and electrical resistivity of hard drawn aluminium wire were studied in this paper. It showed that the electrical resistivity and tensile strength of the wire improved with the increase of Si content, and trace content of Si led to significant increaseof the electrical resistivity. It was analyzed that $\mathrm{Fe}$ dissolved in the $\alpha(\mathrm{Al})$ matrix in form of supersaturated solid solution and its solid solubility was about $0.03 \%$. Similarly $\mathrm{Si}$ dissolved in $\alpha(\mathrm{Al})$ in form of solid solution when its content was low, and with the content increased to certain content, redundant $\mathrm{Si}$ would precipitate as secondary phase transforming from $\mathrm{AlFe}$ binary compound to $\mathrm{AlFeSi}$ ternary intermetallic compound of $\alpha\left(\mathrm{Al}_{12} \mathrm{Fe}_{3} \mathrm{Si}_{2}\right)$ then $\beta\left(\mathrm{Al}_{9} \mathrm{Fe}_{2} \mathrm{Si}_{2}\right)$ phase.
\end{abstract}

Keywords: Silicon content, hard drawn aluminium wire, electrical resistivity, tensile strength, secondary phase.

\section{Introduction}

Commercial pure aluminium is a kind of important conductive material for its good electrical conductivity, and its strength will be improved by way of mechanical treatment such as drawing. Hard drawn aluminium wire was widely used in overhead transmission wire whose conductivity depends on aluminium purity and quantity and existence state of impurities. As a normal impurity, Si influenced strongly on mechanical and electrical properties of hard drawn aluminium wire. Due to high cost of super pure aluminium, it's significant to focus on the influences of $\mathrm{Si}$ quantity and existence state on conductivity properties of hard drawn aluminium wire.

\footnotetext{
*Corresponding author: xuxuexia2008@163.com
} 


\section{Experimental Materials and Procedures}

\subsection{Experimental Materials}

The wire production process includes aluminium ingot remelting, microalloying, rod casting, cold rolling and single wire drawing. The influence of $\mathrm{Si}$ on properties of hard drawn aluminium wire was studied by adding Si, Fe into A199.99 super pure aluminium, Si and $\mathrm{Fe}$ were added in form of interalloy as Al-12.68Si and Al-3.66Fe. Chemical composition of experimental super pure aluminium and experimental alloy were shown in Table 1 and Table 2 respectively.

Table 1 Chemical Composition Of The A199.99 Aluminum For Experiment, Ppm

\begin{tabular}{ccccccccccc}
\hline $\mathrm{Si}$ & $\mathrm{Fe}$ & $\mathrm{Cu}$ & $\mathrm{Mg}$ & $\mathrm{Cr}$ & $\mathrm{Mn}$ & $\mathrm{V}$ & $\mathrm{Ti}$ & $\mathrm{Zr}$ & $\mathrm{B}$ & $\mathrm{Ga}$ \\
\hline 17.9 & 17.4 & 0.2 & 1.3 & 1.5 & 4.7 & 5.1 & 1.6 & 1.5 & 1.8 & 11.2 \\
\hline
\end{tabular}

Table 2 Chemical Composition Of The Experimental Alloy

\begin{tabular}{|c|c|c|}
\hline Alloy serial number & Si content(wt\%) & Fe content(wt\%) \\
\hline S1 & 0.0018 & 0.120 \\
\hline S2 & 0.0094 & 0.120 \\
\hline S3 & 0.068 & 0.109 \\
\hline S4 & 0.085 & 0.115 \\
\hline S5 & 0.118 & 0.111 \\
\hline S6 & 0.131 & 0.115 \\
\hline S7 & 0.142 & 0.111 \\
\hline
\end{tabular}

\subsection{Experimental Procedures}

The experimental procedure includes aluminium ingot remelting, micro-alloying, rod casting, cold rolling and drawing. Firstly, put super pure aluminium ingot in the furnace heated to $750^{\circ} \mathrm{C}$, then added alloy and refined for $45 \mathrm{~min}$. Secondly, cast the refined aluminium melt directly to be $22 \mathrm{~mm}$ square rod. Thirdly, rolled the cast rod to be round rod with diameter of $9.5 \mathrm{~mm}$ during 10 passes of deformation. Finally, aluminium wire was obtained after several passes of drawing on ZJ-450 drawing machine.

The electric resistivity was measured by DQ-1 bridge fixture and SB2230 DC digital resistivity tester. The tensile test was carried out on SANS CMT 5105 tensile testing machine.

\section{Results and Discussions}

\subsection{Influence of Si and Fe Content on Properties of Aluminium Alloy Wires}

The tensile strength and electric resistivity of aluminium alloy wires with different quantities of $\mathrm{Si}$ and $\mathrm{Fe}$ were shown in Table 3. In addition, the effect of $\mathrm{Si}$ content on tensile strength of hard drawn aluminium wire was illustrated in Fig.1. 
Table 3 Relationship Between The Si Content And The Tensile Strength Of Aluminium Alloy Wire

\begin{tabular}{|c|c|c|c|}
\hline Sample number & Si content, $\quad \mathrm{wt} \%$ & $\mathrm{Rm}, \mathrm{MPa}$ & Resistivity, $\mathrm{n} \Omega \cdot \mathrm{m}$ \\
\hline S1 & 0.0018 & 159.04 & 27.5457 \\
\hline S2 & 0.0094 & 157.22 & 27.6273 \\
\hline S3 & 0.068 & 184.91 & 27.8509 \\
\hline S4 & 0.085 & 191.86 & 27.9521 \\
\hline S5 & 0.118 & 199.41 & 28.0714 \\
\hline S6 & 0.131 & 192.03 & 28.1743 \\
\hline S7 & 0.142 & 196.63 & 28.2577 \\
\hline
\end{tabular}

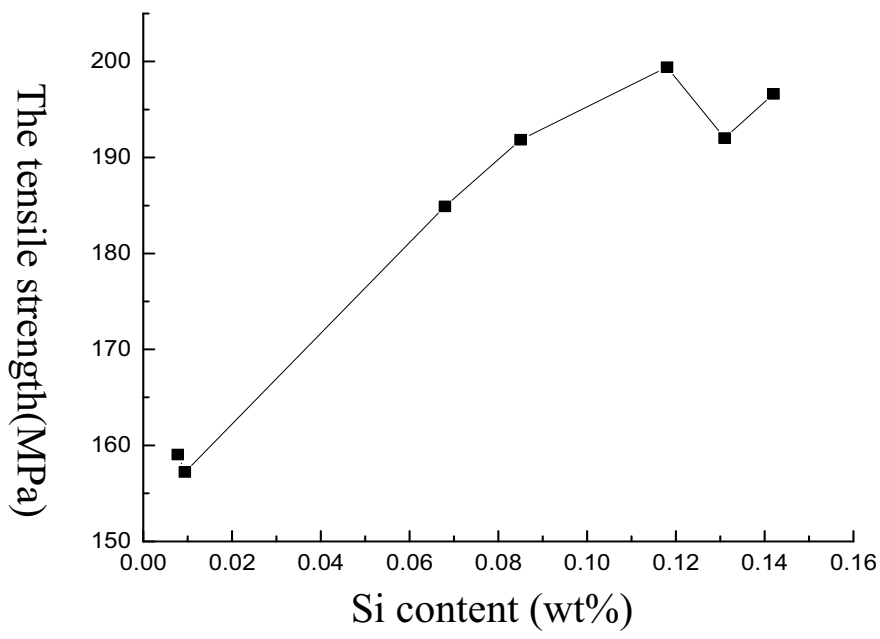

Fig.1 Effect of Si content on tensile strength of hard drawn aluminium wire

Both Table 3 and Fig. 1 exhibited obvious relationship between tensile strength and $\mathrm{Si}$ content that the former increasedwith the increasing of the latter, and the tendency weakened till $\mathrm{Si}$ content reached $0.1 \%$, then the tensile strength behaved a small decrease corresponding with higher Si content.

$\mathrm{Si}$ in aluminium alloy either resolved in $\mathrm{Al}$ matrix to form $\alpha$-Al solution or precipitated from Al matrix in form of intermetallic compound by reacting with impurity element especially Fe. Different states correspond with different effects on properties of commercial pure aluminium. Due to ineviTable existence of $\mathrm{Fe}$ in commercial pure aluminium and its interplay with $\mathrm{Si}$, commercial pure aluminium can be taken as $\mathrm{Al}-\mathrm{Fe}-\mathrm{Si}$ alloy. Researches[1,2] indicated that under small quantities of $\mathrm{Fe}$ and $\mathrm{Si}, \alpha-\mathrm{Al}_{12} \mathrm{Fe}_{3} \mathrm{Si}_{2}$ and $\beta-\mathrm{Al}_{9} \mathrm{Fe}_{2} \mathrm{Si}_{2}$ would form as well as $\alpha-\mathrm{Al}, \mathrm{FeAl}_{3}$ and $\mathrm{Si}$ in the alloy. When the quantities of $\mathrm{Fe}$ and $\mathrm{Si}$ were very small, $\mathrm{Si}$ tended to exist in form of solution, whereas Fe was likely to precipitate as $\mathrm{FeAl}_{3}$. When $\mathrm{Fe}$ and $\mathrm{Si}$ reach a certain amount, ternary compounds would precipitate whose type depended on the $\mathrm{Fe} / \mathrm{Si}$ ratio. When $\mathrm{Fe} / \mathrm{Si}>1$, the precipitation was $\alpha-\mathrm{Al}_{12} \mathrm{Fe}_{3} \mathrm{Si}_{2}$, When $\mathrm{Fe} / \mathrm{Si}<1$, the precipitation was $\beta-\mathrm{Al}_{5} \mathrm{FeSi}$. Both compounds separated matrix and deteriorated properties of the alloy. Because $\alpha-\mathrm{Al}_{12} \mathrm{Fe}_{3} \mathrm{Si}_{2}$ was less harmful than $\beta-\mathrm{Al}_{9} \mathrm{Fe}_{2} \mathrm{Si}_{2}, \mathrm{Fe} / \mathrm{Si}$ ratio should be controlled to ensure the tendency of $\alpha-\mathrm{Al}_{12} \mathrm{Fe}_{3} \mathrm{Si}_{2}$ formation. It was recommended that Fe was lower than $0.16 \%$, Si was lower than $0.08 \%$ and $\mathrm{Fe} / \mathrm{Si}$ ratio ranged 2 3[3]. 
The reason for the decrease of tensile strength with continuous addition of $\mathrm{Si}$ was assumed as follows: when Si quantity was small, it would dissolve entirely in the alloy while Fe precipitated in form of Al-Fe compounds, leading to the increase of tensile strength. But with continuous addition of $\mathrm{Si}, \mathrm{Al}-\mathrm{Fe}$ compound transformed to $\mathrm{AlFeSi}$ ternary compound hence Si partly precipitated as ternary compound and purify matrix. Because stacking fault energy of Al pure matrix was increased, dislocations were hard to decompose and could make use of slip to overcome obstacles, therefore it had high mobility. With the deformation increased, cellular substructure formed quickly due to dislocation multiplication and movement. When distortion energy increased to some extent during rolling process, dislocation could happen recovery by way of slide and slip under elastic stress field, that released lots of distortion energy and relieve internal stress therefore decrease deformation resistance. Tendency to hard or soft relied on comprehensive effects of hardening and softening during deformation period. Soften phenomenon appeared for this kind of alloy because softening tendency overwhelmed harden when rolling rate was over $90 \%[4-6]$

\subsection{Influence of Si Content on Properties of Hard Drawn Aluminium Wire}

The Resistivity of the hard drawn aluminium wire with different silicon content was shown in Table 3 and the relationship between the Si content and the conductivity of aluminium alloy wire was shown in Fig.2. Both Table 3 and Fig.2 indicated that with quantity of Fe increased from $0.012 \%$ to $0.120 \%$, resistivity only changed $7.242 \mathrm{n} \Omega \cdot \mathrm{m} / \omega \mathrm{t} \%$. Whereas when Si increased from $0.0078 \%$ wt to $0.0094 \%$ wt, resistivity changed notably as $10.736 \mathrm{n} \Omega \cdot \mathrm{m} / \omega \mathrm{t} \%$. In addition, continuous increase of Si led to resistivity increase ranging $3.5 \sim 7 \mathrm{n} \Omega \cdot \mathrm{m} / \%$ wt.

Table 4 Resistivity Of The Hard Drawn Aluminium Wire With Different Silicon Content

\begin{tabular}{|c|c|c|c|c|}
\hline $\begin{array}{c}\text { Sample } \\
\text { number }\end{array}$ & $\begin{array}{c}\text { Si content, } \\
\mathrm{wt} \%\end{array}$ & $\begin{array}{c}\text { Fe content, } \\
\mathrm{wt} \%\end{array}$ & $\begin{array}{c}\text { Resistivity, } \\
\mathrm{n} \Omega \cdot \mathrm{m}\end{array}$ & $\begin{array}{c}\text { Resistivity change rate, } \\
\mathrm{n} \Omega \cdot \mathrm{m} / \omega \mathrm{t} \%\end{array}$ \\
\hline $\mathrm{C}$ & 0.0018 & 0.012 & 26.7636 & $/$ \\
\hline $\mathrm{S} 1$ & 0.0018 & 0.120 & 27.5457 & 7.242 \\
\hline S2 & 0.0094 & 0.120 & 27.6273 & 10.736 \\
\hline S3 & 0.068 & 0.109 & 27.8509 & 3.815 \\
\hline S4 & 0.085 & 0.115 & 27.9521 & 5.954 \\
\hline S5 & 0.118 & 0.111 & 28.0714 & 3.613 \\
\hline S6 & 0.131 & 0.115 & 28.1743 & 7.915 \\
\hline S7 & 0.142 & 0.111 & 28.2577 & 7.589 \\
\hline
\end{tabular}




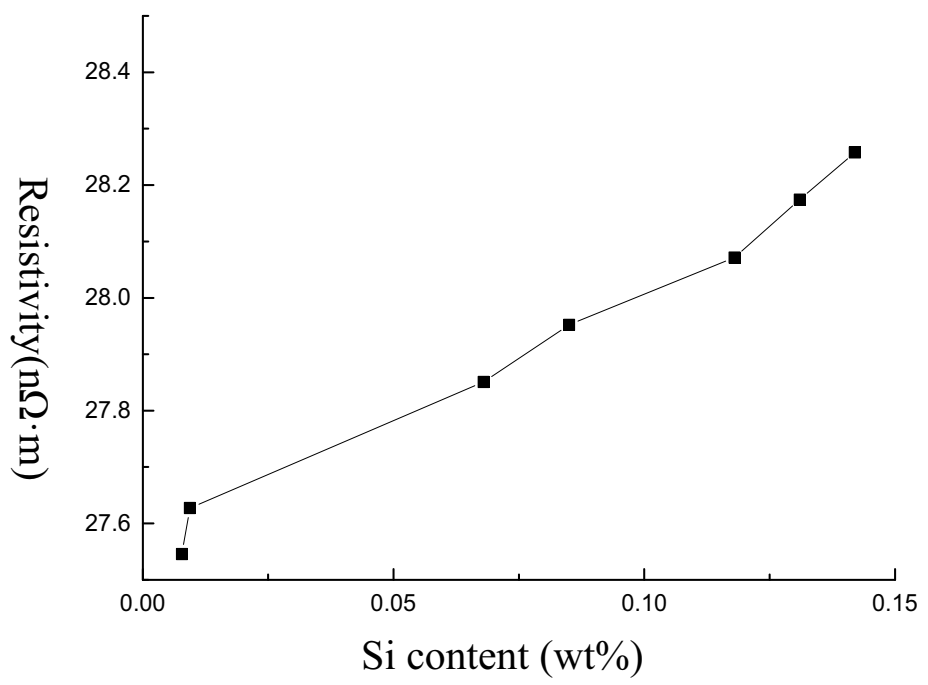

Fig.2 relationship between the Si content and the conductivity of aluminium alloy wire

\subsection{The Effects of Fe and Si States on Properties of Aluminium Wire}

The influence of different existence states of $\mathrm{Fe}$ and $\mathrm{Si}$ in aluminium alloy on resistivity was shown in Table 5. From Table 5 it was indicated that the influence value of solute Fe on resistivity was $25.6 \mathrm{n} \Omega \cdot \mathrm{m} / \omega \mathrm{t} \%$, whereas that of C and S1 were only $7.242 \mathrm{n} \Omega \cdot \mathrm{m} / \omega \mathrm{t} \%$. Because $\mathrm{Fe}$ was impossibly to precipitate under cold rolling condition, with consistent $\mathrm{Fe}$ content, change of resistivity could be combined with content and existence state of $\mathrm{Si}$. Experiments[4-8] found that Fe solubility was only $0.08 \omega \mathrm{t} \%$ when cast rod was $30 \mathrm{~mm}$ in diameter and cooling rate was $1^{\circ} \mathrm{C} / \mathrm{s}$ higher than that in present experiment. According to Table 4, Fe solubility could be estimated to be only $0.03 \omega t \%$ under present experimental condition that was lower than research data. Comparing data of S1 and S2, a very small quantity of $\mathrm{Si}$ could influence resistivity largely, about $10.2 \mathrm{n} \Omega \cdot \mathrm{m} / \omega \mathrm{t} \%$ according to research. When $\mathrm{Fe} / \mathrm{Si}$ ratio was higher than 3 and aluminium purity was higher than $98.5 \%$, Fe would existed as Al-Fe compounds and Si became entirely soluble in the alloy[9]. When Si was added continuously, resistivity increased higher than research reported of influence of precipitating $\mathrm{Si}$ on resistivity. The causes may be that some Si dissolved in alloy when its quantity increased[10].

Table 5 Effect Of The State Of Impurity Elements On The Resistivity Of Aluminium[11]

\begin{tabular}{|c|c|c|}
\hline Elements & $\mathrm{Si}$ & $\mathrm{Fe}$ \\
\hline Resistivity increment & 10.2 & 25.6 \\
$\mathrm{n} \Omega \cdot \mathrm{m} / \omega \mathrm{t} \%$ & 0.88 & 0.58 \\
\hline
\end{tabular}

An interesting phenomenon appeared that resistivity change rate fluctuated when $\mathrm{Fe} / \mathrm{Si}$ ratio was about 1 . It was assumed that the precipitation phase transformed from $\alpha-\mathrm{Al}_{12} \mathrm{Fe}_{3} \mathrm{Si}_{2}$ to $\beta-\mathrm{Al}_{9} \mathrm{Fe}_{2} \mathrm{Si}_{2}$, their influences on resistivity of aluminium alloy were different and the exact result need further research. 


\section{Conclusions}

1. Tensile strength of hard drawn aluminium wire increased with the increasing of Si content. The tendency was obvious in early stage and became weaken when Si content reached $0.1 \omega t \%$. There was an apparent soften phenomenon when $\mathrm{Si}$ content reached $0.118 \omega \mathrm{t} \%$ because secondary precipitation phase purified the matrix so as to diminish deformation resistance.

2. Resistivity of commercial pure aluminium increased with the the increasing of $\mathrm{Si}$ content. The tendency was obvious in early stage with resistivity rate as 51.018 $\mathrm{n} \Omega \cdot \mathrm{m} / \omega \mathrm{t} \%$. While when $\mathrm{Si}$ content exceeded solution point, the resistivity change rate decreased to 3.5 7 $\mathrm{n} \Omega \cdot \mathrm{m} / \omega \mathrm{t} \%$. The state of $\mathrm{Si}$ depended on $\mathrm{Fe} / \mathrm{Si}$ ratio, when the ratio was larger than 3 and Aluminium purity larger than $98.5 \%$, Fe existed as Al-Fe compounds and Si existed as solution entirely, whereas when Si content increased it existed as secondary precipitation phase.

\section{Acknowledgments}

This work was financially supported by State Grid Corporation of China, Grant No. 5204HB140002.

\section{References}

1. Fu Gaosheng, Kang Jixing, Analysis and research on effects of $\mathrm{Fe}$ and $\mathrm{Si}$ in commercial pure aluminium. Special casting \& nonferrous alloys.(1)(1999)29 31.

2. Yang Jiangbo, Yin Fei, Improvement of the Morphology of iron phase in alloys, Casting. 49(8)(2000)454-459.

3. Wang Rongli, He Zhengfu, Wang Ruyi, Effect of Si, Fe on the Conductivity of Electrical Aluminium Rod. Nonferrous metals processing.38(5)(2009)10-12, 50.

4. Li Fengzhen, Liu Zhaojing, Jin Quan, et.al, Effect of iron on the work-softening of Al-Fe Alloy. Journal Harbin Uni. Sci.\& Tech..2(6)(1997)26-28.

5. Liu Zhaojing, Yu Zemin, Li Fengzhen, et.al, The effect of iron content on the Rolling softness of Al-Fe Alloys. Journal Harbin Uni. Sci.\& Tech..18(4)(1994) 41-43.

6. Jin Quan, Li Fengzhen, Yu Zemin, et.al, Influence of uniformization on work softening of Aluminum-ferro alloy.Journal Harbin Uni. Sci.\& Tech.1(2)(1996)33-35.

7. Holm K., Hornbogen E., Annealing of supersaturated and deformed A1-0.042wt $\% \mathrm{Fe}$ solid solutions. Journal of materials science.5(8)(1970)655-662.

8. A.Griger, V. Stefaniay, Equilibrium and non-equilibrium intermetallic phases in Al-Fe and Al-Fe-Si alloys. Journal of Materials Science. 31(1996)6645-6652

9. B.Dutta, M.Rettenmayr, Effect of cooling rate on the solidification behaviour of Al-Fe-Si alloy. Materials Science and Engineering A. 283(2000) 218-224.

10. Liu Dongyu, Li Wenjie, Design of aluminium alloy conductor with high conductivity and heat resistance. Transactions of materials and heat treatment. (6)(2014)17 21.

11. Zheng Xuan, Discussion of chemical composition of aluminium foil. Light Alloy Fabrication Technology, 21(1)(1993)18-22. 